\title{
Design of e-Land Record Information System with Google Map Using Mobile Commerce
}

\author{
Kanwalvir Singh $^{1}$, Himanshu Aggarwal $^{2}$ \\ ${ }^{1}$ CSE \& IT Department, B.B.S.B.Engg.College, Fatehgarh Sahib, India; ${ }^{2}$ UCOE, Punjabi University, Patiala, India. \\ Email: kdhindsa@gmail.com, himanshu.pup@gmail.com
}

Received February $7^{\text {th }}, 2013$; revised March $10^{\text {th }}, 2013$; accepted March $18^{\text {th }}, 2013$

Copyright (c) 2013 Kanwalvir Singh, Himanshu Aggarwal. This is an open access article distributed under the Creative Commons Attribution License, which permits unrestricted use, distribution, and reproduction in any medium, provided the original work is properly cited.

\begin{abstract}
e-Governance facilities are being used nowadays by citizens in various Government projects of the country. But the integration of mobile technologies with the e-Governance projects can lead to more human interaction and benefits for the society as a whole. This will result in having more impact on the lives of the common citizens and increase in awareness of such e-Governance projects. The paper introduces the features, technologies and design of the Android mobile device application, mobileLoanapp for the customer (client) of the bank for the loan approval process. The e-Land record information system has been designed and implemented with Google Map using Mobile Commerce by developing this mobile app. This m-app has been developed so as to provide improved and flexible e-Governance facility to the common citizens of the country. The proposed system if adapted will pave the way for the real-time applications to be embedded with the e-Governance facilities. This paper presents the overall system architecture along with its functional components and scope of the very appealing m-application (mobileLoanapp) for bank loan approval process in interconnection with the land server (part of Farad Kendra's). The overall advantages of the proposed m-app have also been determined in comparison to the existing e-Governance system, giving a viable option to adopt and make use of integration of mobile technologies for providing e-Governance through this m-app.
\end{abstract}

Keywords: Mobile Technologies; Android; e-Governance; M-App; mobileLoanapp; Google Maps

\section{Introduction}

Mobile phone applications (m-apps) are the buzz words in today's digitized world. The affordability and instant connectivity combined with the convenience features of the mobile phones has resulted in mobile technology holding significant potential for e-Governance projects. M-apps are being extensively used all over the world for entertainment, market, educational, personalization and e-Governance features over wide variety of platforms offered by various mobile phone companies. The e-Governance facilities offered by various departments are being utilized by common citizens of many countries around the world. The improved, flexible and better Governance features offered by such m-apps have brought a major paradigm change to overall thought process of the developing countries. This has resulted in e-Governance applications integration with mobile platforms for making affordable and lightweight mobile phone applications (m-apps). The app stores for Apple iOS, Google Android, Nokia Symbian have been leading the way for develop- ing such wonderful mobile phone applications for usage by the common citizens. The developments of m-apps have led to more of uniform application development standards. This has resulted in increased innovativeness, giving overall advantage to the customers in choosing and selecting from the great pool of m-apps offered by various platforms in this global digitized age. These fullyfeatured and wide-variety m-apps have resulted in the availability (anytime, anywhere)—24 7 of wide variety of remote information at the door step of the facility centric citizens, which was not possible some years ago. Mobile software development is thus paving the way for the future. Various programming languages are being used for developing m-apps such as: Java for Android OS, Visual C\#/C++ for Windows Mobile, Objective-C for iPhone OS, etc.

\section{Mobile-Apps Development Using Android OS-A Brief Overview}

Android is an open-source operating system that uses 
modified version of the Linux kernel and various kinds of API's. Google bought Android in 2005 and has since been popular for developing mobile applications. The private companies could add or modify their own applications and can sell them, without having the need to submit these to the open-source community under the Apache License [1]. Mobile applications are developed for various other mobile platforms such as for iPhoneiOS, Nokia-SymbianOS, J2ME, Blackberry and Windows mobile. Android come under the Open Handset Alliance (OHA). The main advantage of developing mobile application is it's being free, open-source, scalable and its encouragement to the third party development (to use and customize it). The built-in modules can also be improved with modified versions. Another main feature is the portability of applications across variety of architectures since most of the programs are written in Java. The easy customization of user interfaces can be easily done for various screen resolution. Android is optimized for low-power and low-memory devices thus making it more advantageous in comparison to other platforms. Variety of embedded codec does add more to its versatile features as they have been built into it. The embedding of browser and map views in the developed mobile phone applications also add greatly to its functionality.

\section{Literature Review}

Our work has been motivated by some previous work on the use of mobile technologies for the development of mobile applications (m-apps) for real-time projects involved in e-Governance initiatives and for various other real-time application scenarios around the world. The need and importance of the implementation of location based services in Android, providing the clients with services that originate from the geographical location of user's mobile device has been emphasized by Ch. R. Rani et al. [2] in their research work. The work on iOS application for university campus for iPhone, iPod touch and iPod has been done in order to simplify the liveability of the university for students and officials of the university. The scope and features of the application have been discussed for the real-time events and activities associated with the university [3]. The design and implementation of integrated multilingual voting service for conducting elections in Nigeria using Hypertext processor Web platform and Google Android mobile platform in native language has been done by Olaniyi et al., 2011 [4]. The integrated system for a real-world application of emergency medical service (EMS) data system has been proposed to improve the efficiency and effectiveness of the existing data system. The core technologies having hand-held computers, GPS and GIS have all been integrated for the verification, transmission, storage and analysis of the accidental data [5]. The system architec- ture proposed by B. Bhargava et al. [6] had an outdoor navigation application with integrated support for pedestrian crossing guidance, specially made for real-time guidance for blind. W. Lawrence et al. [7] worked on the application of biometric security in agent based hotel booking system using Android OS using SSL (Secure Socket Layer) on the internet. Android 2.2 enabled mobile phone with JADE-LEAP agent development kit has been used for the purpose. R. P. Padhy et al. [8] developed cloud based rural healthcare information system model along with its functional components to facilitate and improve the quality of patient care. The systematic performance of Android platform has been studied and analyzed using benchmark application and public profile software. DDMS and Traceview-Android SDK tools were used to study the application and framework performance of Android OS [9].

\section{Existing System-Issues (Challenges)}

The Farad Kendra's (Farad centres) have been established at various district Tehsils and sub-Tehsils of the various states in India. This has been done so as to provide automated computerization of the revenue (land) records \& better e-Governance to the common citizens of the country. The bank and Farad Kendra's (land record centres) are distantly located far away from the reach of common citizens, especially rural citizens who have to reach from remote places for availing services. The loan approval process of bank can be approved after the authenticated land records and relevant documents are shown to the bank officials. This is possible only after facing much hurdles, paper work and unnecessary harassment of the customer. This unsatisfied service results in sheer time-wastage and much struggle for the customer. Still many deficiencies (issues) that exist in the recent system are as detailed below:

- Revenue officials are still pursuing with traditional methods.

- Distance to be travelled for reaching Farad Centre.

- Lack of awareness about establishment of Farad Centre (Farad Kendra's).

- Time-consuming process.

- Power (electricity) problems at the Farad Kendra's.

- No support, training or guidance to the citizens.

- Staff/operator problems at the centres.

- Procedural hassles (Documentation work).

- Illiteracy problem.

- Malpractices by officials.

- Non-transparency of revenue records.

- Non-availability of Kiosks (self-operated system).

\section{Proposed System-Design \& Architecture}

Figure 1 depicts the overall workflow of the proposed 


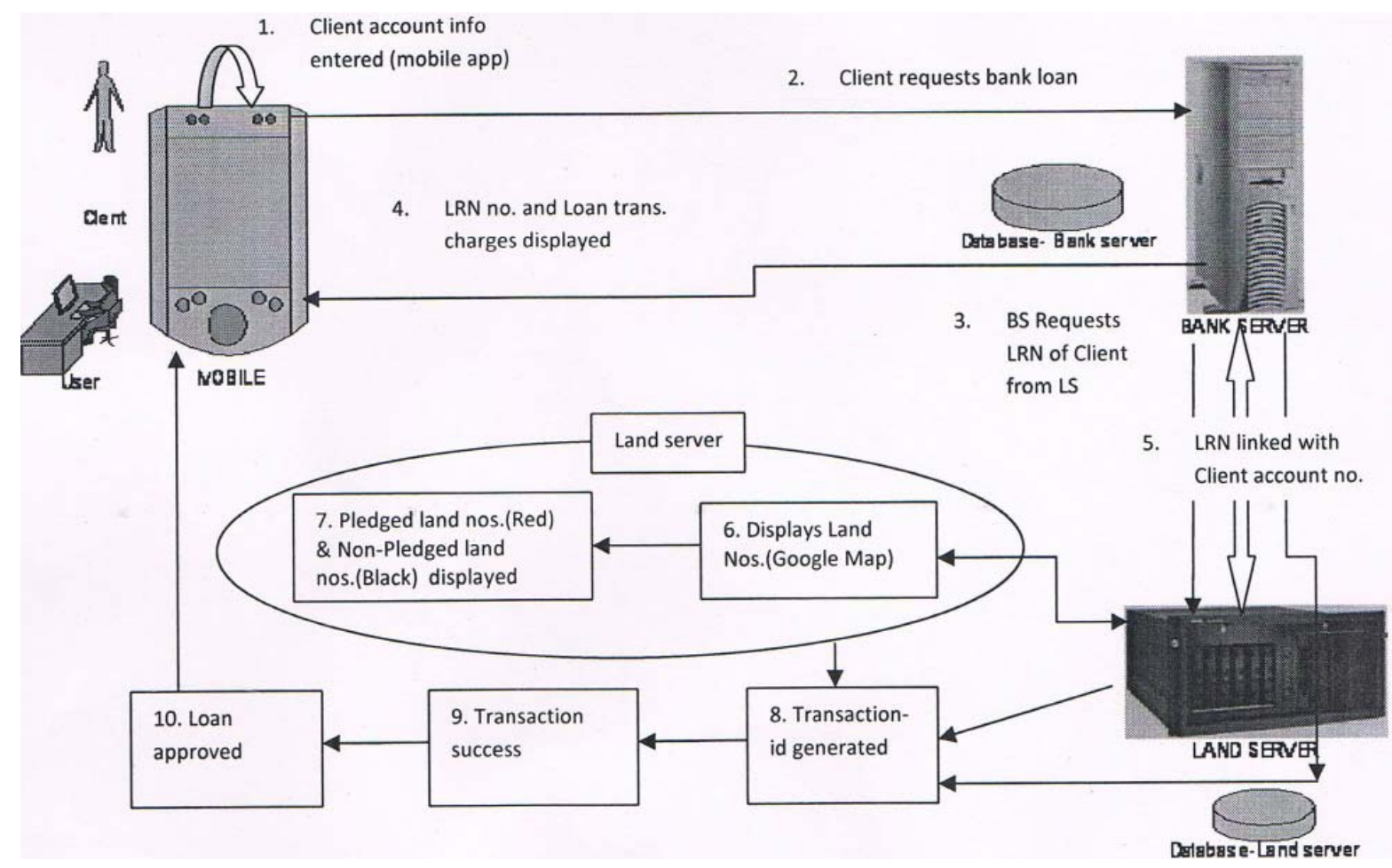

Figure 1. Workflow of the proposed system.

system. It also represents the overview of the distributed network architecture of the proposed system.

The various steps for the workflow of the proposed system are as follows:

Step 1. Client's personal information entered on mobile phone application.

Step 2. Client requests bank loan service from mobile phone app of Bank.

Step 3. Bank server requests land record no. (LRN) of client from the land server (LS).

Step 4. Land record no. (LRN) and Loan trans. charges displayed.

Step 5. Land record no. (LRN) linked with client's account no. displayed.

Step 6. Land server displays client's land nos (Displayed on Google Map).

Step 7. Pledged land nos. (Red colour) \& Non-pledged land nos. (Black colour) displayed.

Step 8. Transaction-id of the process generated to the client.

Step 9. Transaction (loan approval) is successful.

Step 10. Loan approved. Bank sends SMS to client to visit personally at specific date $\&$ time.

\section{Implementation}

\subsection{Development Tools-Hardware/Software Used}

The following software tools have been deployed to develop the project. Linux (Ubuntu ver. 12.04.1) operating system is used for this project. The front-end used is PHP 5 and the backend is MySQL 5.5.24. The framework used is Eclipse SDK 4.2. The Android Development Tools (ADT) plug-in for Eclipse and Android Software Development Kit 2.3 (Android SDK) have been used as the development tools. The emulator used is gtab. Java 6 is the language used with Java development Kit (JDK) and Java Virtual machine (JVM). The application developed is lightweight application with the total size of the project being approx 450 kbs (kilobytes) only.

\subsection{Components of Proposed Model}

The proposed system consists of three components mainly:

1) Mobile phone application (mobileLoan app): Device application (app runs on mobile phone).

2) Bank server: Authentication server of the bank (maintains customer personal info \& record).

3) Land server: Authentication server of the revenue department (maintenance of land records).

$>$ The various modules (files) of the project are as follows:

1) Bank server: index, loginproc, config, securedpage.

2) Land server: index, config, lrn, list, process, land, trans, logout.

3) Other files: database.sql, log, req, style2.css, readme.

The project can be run with the following command on 
the Mozilla Firefox browser 16.0.1: http://localhost/bank/index.php.

\subsection{Analysis: Sequence-Diagram of the Model}

StarUML ver.5.0 is the tool used for analysis and design of the proposed model in UML (unified modelling language). StarUML is an open-source project for developing fast, extensible, and freely-available UML/MDA platform. The structure of the proposed model has been analyzed using the UML sequence diagram. Sequence diagram (Figure 2) here depicts the overall flow (stepby-step) of the proposed model from left > right direction.

\section{Discussions}

The Transaction-I (for Pledged land) and Transaction-II (for non-pledged land) of the proposed system are as explained below:

\subsection{Transaction-I: For Pledged Land}

The various steps of the Transaction-I for pledged land are explained as below:

Step I. Client (customer) wants to avail loan from a particular bank. Logs into the bank application service (Bank Loan Service) on mobile using his/her account no. and password. The client has already registered his/her mobile number with the bank earlier for availing this facility. The information is generated from the bank server. (Figure 3-index).

Step II. Balance amount of the user's account is shown \& user applies for loan. The transaction is done with the bank server. The database (back-end) of the bank server retrieves the client id record (Figure 4-securedpage).

Step III. The full particulars and the personal information of the client is shown on mobile app. Land record no. (LRN) and loan transaction charges for availing this facility are shown to the user. This information (Figure 5-lrn) is generated from the land record server which retrieves the LRN record from its back-end (database).

Step IV. Proceeding from the LRN from Step 3, the mobile app takes to the Google map where full land record numbers (Land 1, Land 2, Land 3) are shown in Figure 6 (list). In this case, Land 1 and Land 3 are already pledged land (can't be availed for loan) while Land 2 is non-pledged (can be availed for loan). Land 3 is touched on mobile app for availing loan on this land number 3.

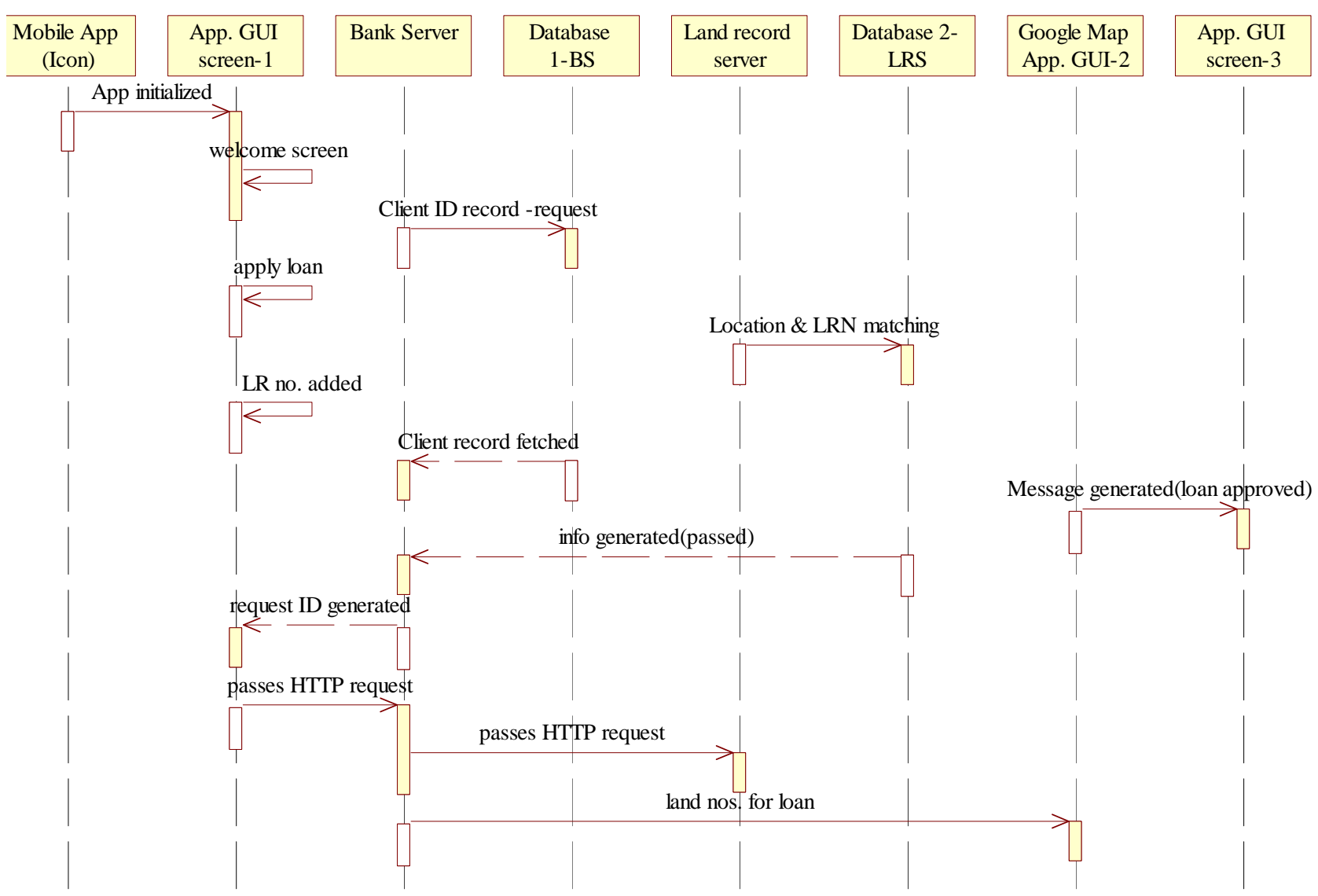

Figure 2. Sequence diagram of the proposed system. 
Step V. Transaction id is generated \& request is processed from the land server (Figure 7 -process).

Step VI. Loan is not available as Land 3 is already pledged. Registration id (for land already registered) and total balance in user's saving account is generated. (Figure 8-land).

Figures (3)-(8) represent the snapshots of the project for Transaction-I (for pledged land).

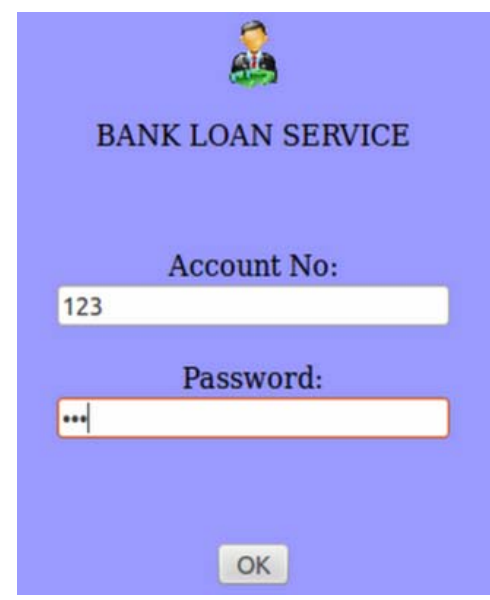

Figure 3. Login page (index).

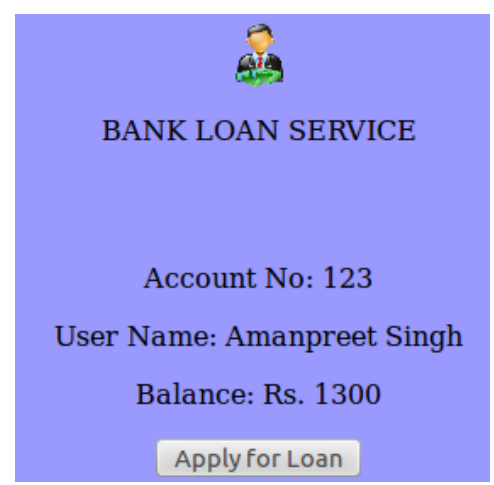

Figure 4. Loan applied (securedpage).

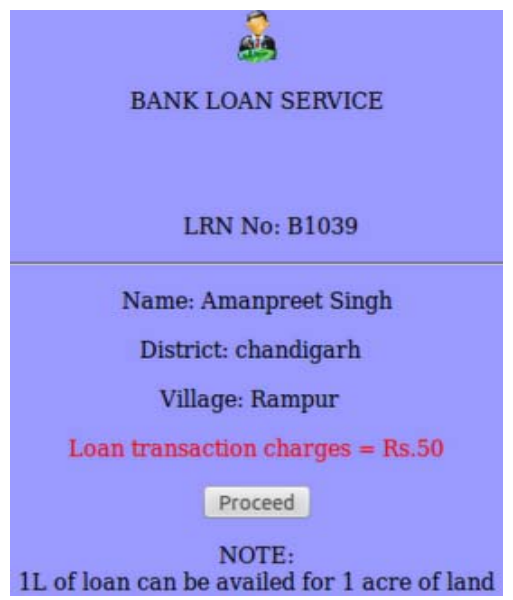

Figure 5. Personal Info \& land transaction charges (Irn).

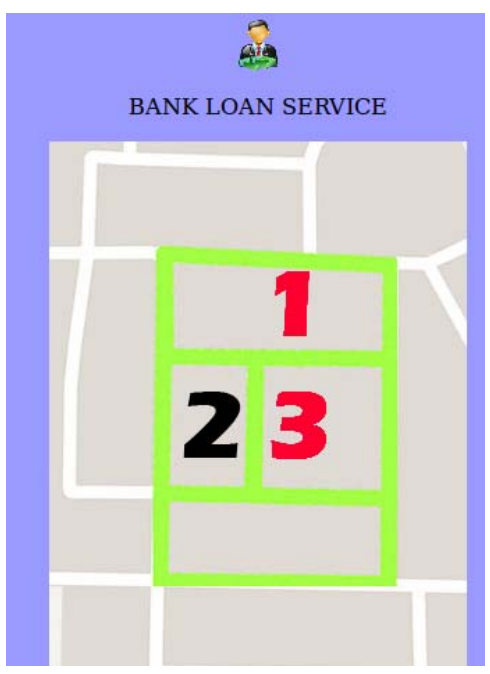

Figure 6. Google Map (list).

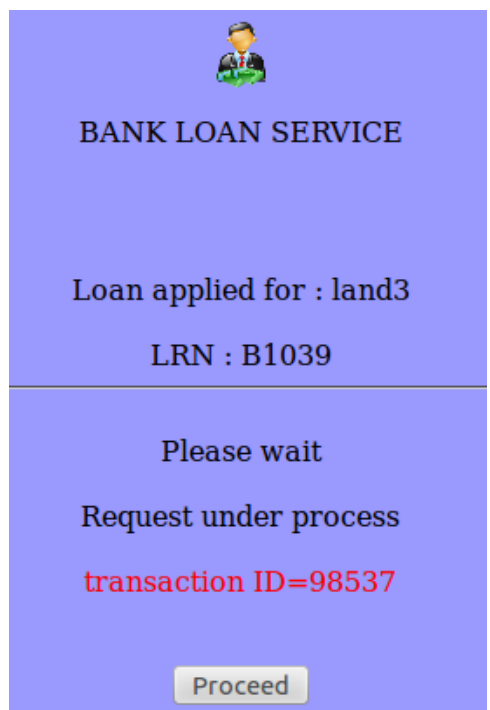

Figure 7. Transaction request (process).

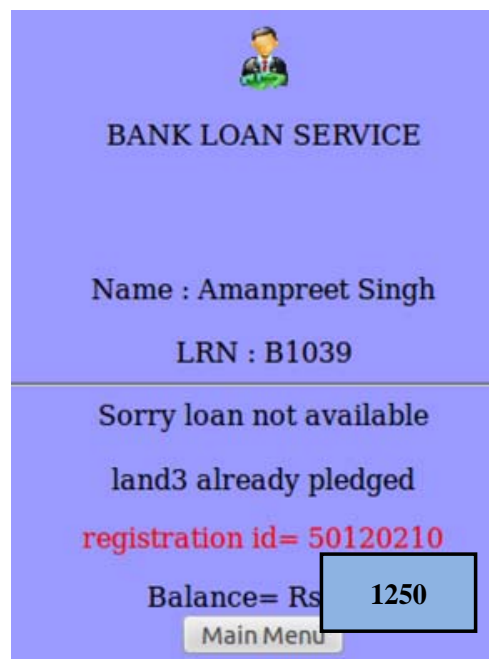

Figure 8. Pledged record (land) 


\subsection{Transaction-II: For Non-Pledged Land}

The various steps of the Transaction-II for non-pledged land are explained as below:

Step I. Client (customer) wants to avail loan from a particular bank. Logs into the bank application service (Bank Loan Service) on mobile using his/her account no. and password. The client has already registered his/her mobile number with the bank earlier for availing this facility. The information is generated from the bank server. (Figure 9-index).

Step II. Balance amount of the user's account is shown \& user applies for loan. The transaction is done with the bank server. The database (back-end) of the bank server retrieves the client id record (Figure 10 — securedpage).

Step III. The full particulars and the personal information of the client is shown on the mobile app. Land record no. (LRN) and loan transaction charges for availing this facility are shown to the user. This information as shown in Figure 11 (lrn) is generated from the land record server which retrieves the LRN record from its back-end (database).

Step IV. Proceeding from the LRN from Step 3, the mobile app takes to the Google map where full land record numbers (Land 1, Land 2, Land 3) are shown in Figure 12 (list). In this case, Land 1 and Land 3 are already pledged lands (can't be availed for loan) while land 2 is non-pledged (can be availed for loan). Land 2 is touched on mobile app for availing loan on this land no. 3.

Step V. Transaction-id is generated \& request is processed from the land server (Figure 13-process).

Step VI. Information that the loan can be availed on Land 2 is processed as it is non-pledged land. (Figure 14-land). Loan amount available is also displayed for Land 2 on the mobile screen.

Step VII. Loan is sanctioned for Land 2. The information about the client (customer) to visit bank personally at particular date and time is displayed on the mobile app. Total balance in user's saving account is generated. (Figure 15-trans).

Figures (9)-(15) represent the snapshots of the project for Transactions-I (for non-pledged land).

\section{Advantages of Proposed System}

The developed mobile phone application (mobileLoan app) has the following advantages:

- Resulting in better e-Governance facility \& flexible service to citizens.

- Remote accessibility of land record: Land records become available from anywhere through mobile phone app connected with bank server and land server.

- Information can be shared seamlessly and in real time across devices and between bank and land record server.
- Transaction charges are automatically debited from client's bank saving account and displayed on the mobile screen.

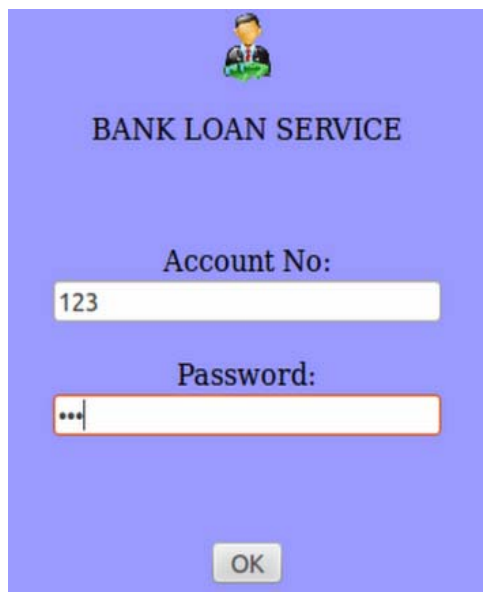

Figure 9. Login page (index).

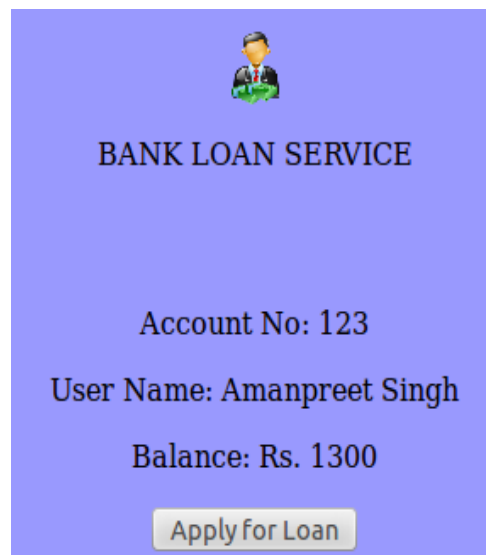

Figure 10. Loan applied (securedpage).

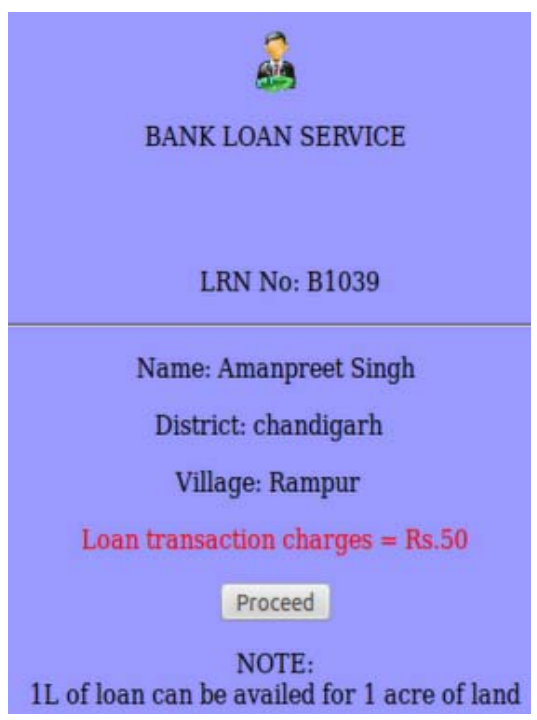

Figure 11. Personal-Info \& land transaction charges (Irn). 


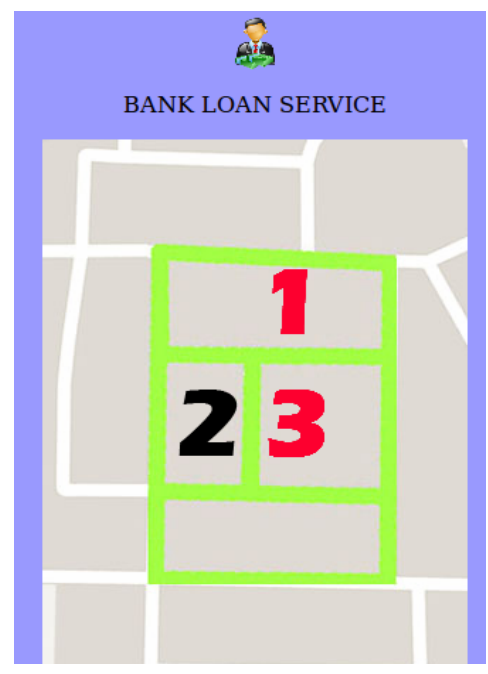

Figure 12. Google Map (list).

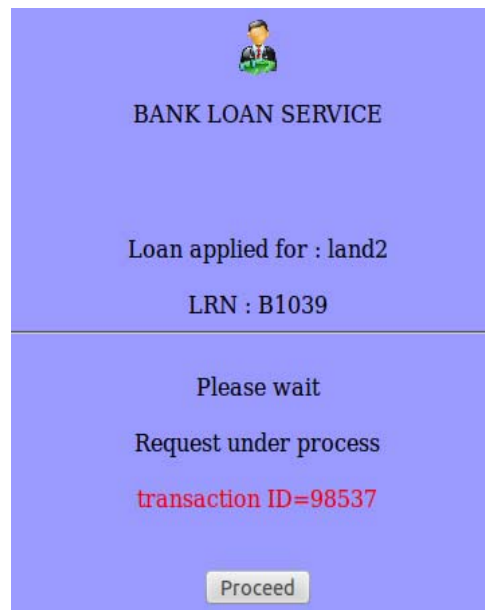

Figure 13. Transaction request (process).

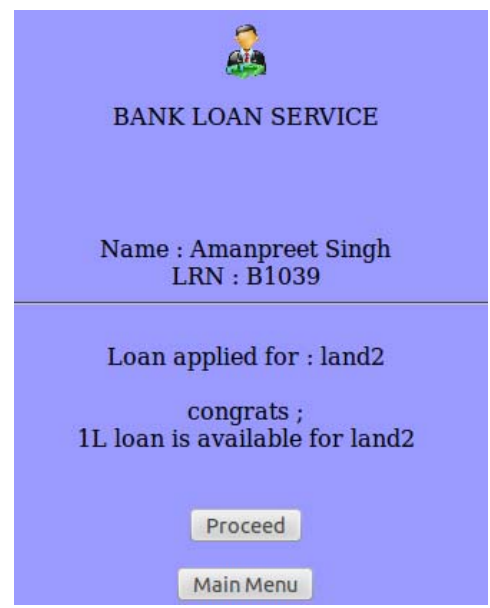

Figure 14. Non-pledged record (land).

- Resulting in more transparency of land records as current status or updation of land records can be checked easily by anyone for authentication.

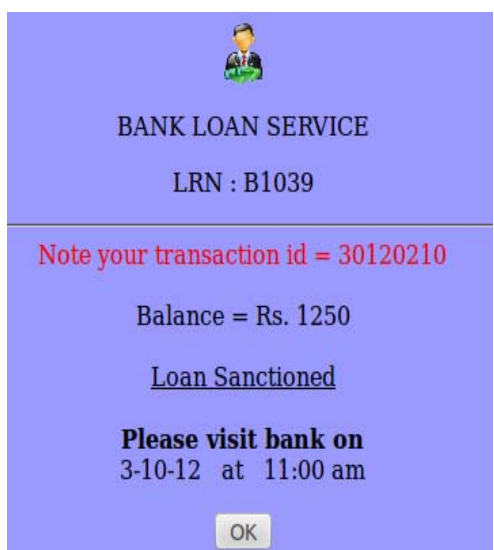

Figure 15. Loan sanctioned (trans).

- Time saving \& Easy clearance of documents of citizens: No need for clients to visit bank personally for getting loan approval or to show documents to the bank officials for getting loan.

- No need for clients to go to revenue department officials (or farad Kendra's) for land authenticity (land pledged/non-pledged) as needed by bank for loan approval.

- Timely delivery of land records: Client gets instant SMS on mobile (after loan has been approved by bank).

- Client need visit bank only once resulting in saving of time and unnecessary harassment for their loan approval at the bank. Bank server in connection with land server verifies the documents of the client.

- Easy to implement across various platforms and devices.

- Elimination of duplicate \& inconsistent record-keeping of land records.

- Reduction in manipulation of land record by other shared land holders (Khewat) due to the record shown on Google map application (for pledged and nonpledged land).

- Significant reduction in paper-work (paperless transactions): Client is saved from unnecessary paper hassles and documents required for loan approval.

- Affordable service (Minimal cost of providing service): Charges are minimal, only internet connection usage charges are levied on the client for making use of mobile application service.

- Easy to track land record (current case-status)-anywhere, anytime $(24 \times 7)$.

Another significant point to note about this m-app developed, mobileLoanapp is that it runs on Spice Mi-270, an Dual SIM Android phone which is the cheapest available till now in India at Rs. 3399 having processor of $416 \mathrm{MHz}$, touch-screen, $2 \mathrm{MP}$ camera and runs on Android v2.2 (Froyo). Spice Mi-270 is available from Saholic, their official online portal. 


\section{Conclusion \& Future Scope}

In this paper, e-Land record information system has been designed and implemented with Google Map using Mobile Commerce by developing this mobile phone application. The mobileLoanapp, a low-cost mobile phone application has been developed for the loan approval process of the bank. Google Map has been used to display the land record images while M-commerce transaction has been done by debiting the transaction charges (for transaction connectivity between the mobile, bank server and land server) from the client's saving account. The development of this m-app, mobileLoanapp results in simplification of the already cumbersome process of getting approval of the loan from the bank. Both the land server (official server of revenue department for providing land records) and the bank server (official server of the bank) work in interconnection to provide authentication personal information about the client (customer) and the relevant authentic land documents. The adoption of mobileLoanApp will thus impact greatly the lives of common citizens, who will be the real benefactor in this case. The combination (integration) of all the advantages of the mobile technologies through this developed mobileLoanapp combined with e-Governance and bank server facilities add greater dimension, scope and versatility to this developed mobile phone application (mobileLoanapp). The local population that has remained reluctant to the use of various existing applications due to the cost of cell phone communication [10] can find solace in using mobileLoanapp. The low-cost design and implementation of mobileLoanapp has thus saved time of the customers \& provided more flexibility and efficiency to the bank and land administration services. The ease of use (no earlier experience required), its lightweight design and impresssive features make this development an application worth of its use. The existence of Wi-Fi network combined with increased Internet usage in the recent times offer great opportunity to the state Government for the deployment of mobileLoanapp. The development of this mobile application can be seen as an opportunity for its further seamless integration with cloud services for the future work.

\section{REFERENCES}

[1] D. Bort, “Android Is Now Available as Open Source," Android Open Source Project. http://source.android.com/posts/opensource

[2] C. R. Rani, A. P. Kumar, D. Adarsh, K. K. Mohan and K. V. Kiran, "Location Based Services in Android," International Journal of advances in Engineering \& Technology, Vol. 3, No. 1, 2012, pp. 209-220.

[3] M. Collotta, G. Pau, V. M. Salerno and G. Scata, "iOS Applications to Improve Learning and Management System in a University Campus," International Journal of Computer Science and Network Security, Vol. 11, No. 3, 2011, pp. 262-267.

[4] O. M. Olaniyi, D. O. Adewumi, E. A. Oluwatosin, O. T. Arulogun and M. A. Bashorun, "Framework for a Multilingual Mobile e-Voting Service Infrastructure for Democratic Governance in Nigeria," 6th International Conference on ICT Applications, Application of ICT to Teaching, Research, and Administration (AICTTRA 2011), Nigeria, 11-15 September 2011, pp. 118-130.

[5] W. Kowtanapanich, Y. Tanaboriboon and W. Chadbunchachal, "An Integration of Hand-Held Computers, GPS Devices and GIS to Improve the Efficiency of EMS Data System," Journal of the Eastern Asia Society for Transportation Studies, Vol. 6, 2005, pp. 3551-3561.

[6] B. Bhargava, P. Angin and L. Duan, "A Mobile-Cloud Pedestrian Crossing Guide for the Blind,” International Conference on Advances in Computing \& Communication (ICACC-11), NIT Hamirpur, April 2011.

[7] W. Lawrence and S. Sankaranarayanan, “Application of Biometric Security in Agent Based Hotel Booking System-Android Environment," International Journal of Information Engineering and Electronic Business, Vol. 4, No. 3, 2012, pp. 64-75. doi:10.5815/ijieeb.2012.03.08

[8] R. P. Padhy, M. R. Patra and S. C. Satapathy, "Design and Implementation of a Cloud Based Rural Healthcare Information System Model," UNIASCIT, Vol. 2, No. 1, 2012, pp. 149-157.

[9] H. J. Yoon, "A Study on the Performance of Android Platform," International Journal on Computer Science and Engineering (IJCSE), Vol. 4, No. 4, 2012, pp. 532537.

[10] N. Patel, D. Chittamuru, A. Jain, P. Dave and T. S. Parikh, "Avaaj Otalo-A Field study of an Interactive Voice Forum for Small Farmers in Rural India,” CHI'2010, Atlanta, April 2010, pp. 733-742. 